\title{
OPTIMALISASI POTENSI WISATA LEMBAH CINTA DAN UMKM DI DESA GAJAH SEBAGAI STRATEGI PEMULIHAN DARI KETERPURUKAN AKIBAT PANDEMI COVID - 19
}

\section{OPTIMIZATION OF POTENTIAL TOURISM OF LOVE AND SMALL AND MEDIUM MICRO ENTERPRISES (UMKM) IN GAJAH VILLAGE AS A RECOVERY STRATEGY FROM DUE TO THE COVID-19 PANDEMIC}

\author{
Almira Aurellia', Dwi Lestari ${ }^{1}$, Ega Putri Novitasari ${ }^{1}$, Laeli Amelia Melani ${ }^{1}$, Lia \\ Lusanti $^{1}$, M. Aji Saputro ${ }^{1}$, M. Wildan Sulthon Al Fikri' ${ }^{1}$, Mochammad Yusuf \\ M. ${ }^{1}$, Nidia Syafira', Pricilia Yuniar Sianggi ${ }^{1}$, Roby Atul Nazila Adawiyah ${ }^{1}$, M. \\ Gandul Atik Yuliani ${ }^{2}$, Wiwin Retnowati ${ }^{3}$

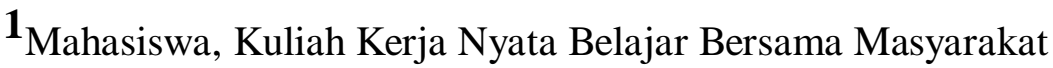 \\ ${ }^{2}$ Fakultas Kedokteran Hewan Universitas Airlangga \\ ${ }^{3}$ Fakultas Kedokteran, Universitas Airlangga \\ e-mail: laeli.amelia.melani-2018@feb.unair.ac.id
}

\begin{abstract}
Gajah Village is one of the villages located in Baureno District, Bojonegoro Regency. In Gajah Village there is Bukit Kapur which is a former mining activity in the form of an elongated basin or valley, residents call it the Valley of Love. However, according to the local village government, there is no management related to the Valley and it is still unknown to the wider community. In addition, in Gajah Village, there are also several Micro, Small and Medium Enterprises (UMKM) actors, the majority of which are in the food sector. However, the current Pandemic period has had an unfavorable impact on MSME players, this impact is on a decrease in sales, in terms of production and distribution. The purpose of the service we carry out is to help introduce the Valley of Love tourism to the wider community by creating a program in the form of video branding that we will upload on various social sites that show the beauty of the Valley of Love behind Gajah Village. In addition, to expand the reach of the UMKM market in Gajah Village so that it can increase sales and turnover from MSMEs during the Covid-19 pandemic. The method used is assistance to the community. The results of our activities are in the form of videos of the charm of the Elephant Village which are uploaded on various social media. The village branding video covers three main elements, namely tourism potential, people's activities, and village harmony. In addition, UMKM branding is by taking photos of products used for marketing through social media.
\end{abstract}

Keywords: Gajah Village, UMKM, Valley of Love 


\begin{abstract}
abstrak
Desa Gajah merupakan salah satu desa yang berada di Kecamatan Baureno, Kabupaten Bojonegoro.Di Desa Gajah terdapat Bukit Kapur yang merupakan bekas kegiatan penambangan yang berbentuk cekungan atau lembah memanjang, warga sekitar menyebutnya Lembah Cinta. Akan tetapi, menurut pemerintah desa setempat, belum ada pengelolaan terkait Lembah tersebut dan masih belum diketahui oleh masyarakat luas. Selain itu, di Desa Gajah juga terdapat beberapa pelaku Usaha Mikro Kecil dan Menengah (UMKM) yang mayoritas di sektor makanan. Akan tetapi masa Pandemi saat ini memberikan dampak yang kurang baik bagi pelaku UMKM, dampak tersebut terdapat pada penurunan penjualan, dalam hal produksi dan distribusi. Tujuan pengabdian yang kami laksanakan adalah membantu mengenalkan wisata Lembah Cinta kepada masyarakat luas dengan cara kami membuat program berupa branding video yang akan kami unggah di berbagai sosial bahwasanya ada keindahan Lembah Cinta di balik Desa Gajah. Selain itu, untuk memperluas jangkauan pasar UMKM yang ada di Desa Gajah sehingga dapat meningkatkan penjualan dan omzet dari UMKM tersebut disaat pandemik Covid-19 ini. Metode yang digunakan adalah pendampingan kepada masyarakat. Hasil kegiatan kami yaitu berupa video pesona Desa Gajah yang diunggah di berbagai media sosial. Video branding desa tersebut mencakup tiga unsur utama yakni potensi wisata, aktivitas penduduk serta harmonisasi desa. Selain itu, branding UMKM dengan melakukan pengambilan foto produk yang digunakan untuk pemasaran melalui media sosial.
\end{abstract}

Kata Kunci : Desa Gajah, Lembah Cinta, UMKM

\title{
PENDAHULUAN
}

Desa Gajah merupakan salah satu desa yang berada di Kecamatan Baureno, Kabupaten Bojonegoro, yang memiliki jarak dari pusat kota sekitar $35 \mathrm{Km}$. Di bagian selatan desa membentang bukit kapur, yang saat ini sudah menjadi cekungan akibat bekas kegiatan tambang. Sebagian besar kegiatan ekonomi penduduk Desa Gajah adalah petani dan buruh, dibuktikan dengan jumlah luas tanah pertanian sawah dan ladang sebesar 217 Ha. Selain sektor pertanian, terdapat pula penduduk yang bekerja di sektor peternakan, perikanan, serta perdagangan.

Pandemi Covid-19 yang mulai terjadi pada awal tahun 2020 sampai saat ini, melanda banyak negara tak terkecuali Indonesia. Berbagai sektor di Indonesia mengalami penurunan, dikarenakan kebijakan Pembatasan Sosial Berskala Besar (PSBB) yang dilaksanakan di beberapa kota di Indonesia sebagai langkah untuk mengurangi rantai penularan Covid-19. Dengan adanya PSBB tersebut sekolah, tempat kerja, tempat ibadah, tempat wisata, dan beberapa fasilitas umum ditutup untuk sementara. Hingga saat ini, pemerintah masih melaksanakan kebijakan baru yang lebih longgar dari PSBB yaitu Pemberlakuan Pembatasan Kegiatan Masyarakat (PPKM). Berbeda dengan PSBB yang menutup sementara beberapa tempat dan fasilitas umum, PPKM ini masih mengizinkan sekolah, tempat kerja, tempat ibadah, tempat wisata, dan beberapa fasilitas umum untuk beroperasi, namun dengan jumlah orang yang sangat dibatasi. Kendati demikian, tetap saja berbagai kegiatan tidak dapat dilaksanakan secara normal seperti saat sebelum pandemi.

Sektor ekonomi dan pariwisata menjadi salah satu sektor yang terdampak cukup besar dari adanya pandemi ini. Usaha Mikro Kecil Menengah (UMKM) mengalami berbagai permasalahan seperti penurunan tingkat penjualan karena pedagang yang biasanya dapat berjualan dengan waktu yang lama, kini memiliki jam buka terbatas serta himbauan pemerintah untuk dirumah saja. Distribusi barang dan jasa juga mengalami hambatan karena adanya pembatasan di berbagai kota di Indonesia yang membuat pelaku UMKM kesulitan memperoleh bahan baku untuk produksi, sehingga menyebabkan 
jumlah produksi mengalami penurunan. Saat ini UMKM yang merupakan salah satu penggerak sektor ekonomi domestik dan penyerap tenaga kerja sedang mengalami penurunan produktivitas yang berakibat pada penurunan omzet dan profit yang sangat signifikan.

Banyak tempat wisata ditutup selama PSBB berlangsung, hal ini menyebabkan kunjungan wisatawan domestik maupun mancanegara mengalami penurunan yang sangat signifikan sehingga pendapatan dari sektor pariwisata mengalami penurunan yang cukup drastis. Saat ini tempat wisata mulai dibuka kembali, dengan jumlah pengunjung yang dibatasi dan tetap mematuhi protokol kesehatan. The World Tourism Organization (UNWTO) atau Organisasi Pariwisata Dunia saat ini mulai mengembangkan visi pariwisata berkelanjutan (sustainable tourism). Menurut UNWTO, pariwisata berkelanjutan didefinisikan sebagai pariwisata yang memperhitungkan dampak ekonomi, sosial, dan lingkungan saat ini dan masa depan, memenuhi kebutuhan pengunjung, industri, lingkungan, dan masyarakat setempat. Panduan UNWTO juga menganjurkan saat ini untuk fokus kepada pasar pengunjung domestik dan dengan menerapkan protokol Kesehatan yang ketat.

Beberapa warga Desa Gajah merupakan pelaku UMKM yang juga terdampak oleh adanya pandemik Covid-19. Sulitnya memperoleh bahan baku dan mahalnya bahan baku yang tersedia, menyebabkan produksi mereka mengalami penurunan. Selain itu produk yang telah diproduksi juga mengalami kesulitan dalam hal penjualan, karena banyak toko yang bisanya menjadi distributor penjualan produk UMKM tersebut, tutup ketika diberlakukannya pembatasan sosial saat pandemik ini. Beberapa toko yang masih buka terkadang tidak lagi mau menjadi distributor atau membeli produk UMKM tersebut, karena sepinya pelanggan. Pelaku UMKM di Desa Gajah saat ini hanya dapat menitipkan produk dagangannya di beberapa toko dan mendapat uang hanya ketika produknya terjual. Bukit kapur yang terletak di bagian selatan di Desa Gajah merupakan bekas dari kegiatan penambangan yang akhirnya membentuk cekungan atau lembah memanjang nan indah yang biasanya disebut sebagai Lembah Cinta oleh penduduk setempat. Menurut pemerintah desa setempat, belum ada pengelolaan terkait Lembah Cinta tersebut. Selain itu belum banyak masyarakat Bojonegoro yang tahu terkait adanya wisata Lembah Cinta di Desa Gajah. Padahal menurut pengamatan kami, Lembah Cinta dapat menjadi destinasi wisata yang dapat memberikan dampak positif dari segi ekonomi dan lingkungan, apabila dikelola dengan baik.

Dari beberapa permasalahan tersebut, kami membuat program bagi UMKM untuk membantu mengenalkan serta memasarkan produknya melalui media massa atau internet. Tujuan kami adalah untuk memperluas jangkauan pasar UMKM yang ada di Desa Gajah sehingga dapat meningkatkan penjualan dan omzet dari UMKM tersebut disaat pandemik Covid-19 ini. Selain itu, melihat potensi wisata Lembah Cinta yang belum dikelola dengan baik sehingga belum banyak orang yang tahu terkait tempat tersebut, maka kami membuat program berupa branding video yang akan kami unggah di berbagai sosial media untuk mengenalkan pada masyarakat luas, bahwasanya ada keindahan Lembah Cinta di balik Desa Gajah.

\section{METODE PENGABDIAN MASYARAKAT}

Metode yang digunakan dalam pengabdian Optimalisasi Potensi Wisata Lembah Cinta dan Produk Usaha Mikro Kecil dan Menengah (UMKM) di Desa Gajah 
sebagai Strategi Pemulihan dari Keterpurukan Akibat Pandemi Covid-19 adalah pendampingan kepada masyarakat. Menggunakan Metode tersebut karena bertujuan untuk mendeskripsikan atau menafsirkan suatu peristiwa dan tindakan dalam situasi tertentu serta untuk memahami obyek penelitian yang lebih mendalam. Metode ini digunakan untuk menjelaskan fenomena sedalam-dalamnya informasi melalui pengumpulan data tentang fakta yang ada di lapangan (Kriyantono, 2006).

Metode observasi dilakukan dengan melakukan pengamatan, tim pelaksana secara aktif turun ke lapangan untuk mengumpulkan data dan melakukan pendampingan. Pendampingan ini untuk mengasilkan potensi kondisi wilayah yang dapat menghasilkan produk wisata serta produk Usaha Mikro Kecil dan Menengah (UMKM ) yang ada pada wilayah tersebut. Sehingga pelaksanaan pengabdian dapat menemukan solusi atas data yang diperoleh untuk dapat mengoptimalkan potensi wisata dan produk UMKM pada Desa Gajah Kecamatan Baureno Kabupaten Bojonegoro sebagai upaya mempertahankan stabilitas ekonomi masyarakat desa ditengah ancaman Pandemi Covid-19.

\section{HASIL DAN PEMBAHASAN}

Program Kuliah Kerja Nyata untuk mengoptimalkan potensi wisata bukit cinta dan UMKM (Usaha Mikro Kecil Menengah) di Desa Gajah akibat keterpurukan yang disebabkan oleh pandemi COVID-19 telah dilakukan oleh kelompok $58 \mathrm{KKN}$ BBM Universitas Airlangga di Desa Gajah Kecamatan Baureno Kabupaten Bojonegoro. Kegiatan ini ditujukan untuk para pelaku usaha mikro di Desa Gajah. Kegiatan yang dilakukan pada tanggal 2 Februari 2021 pada pukul 09.00 WIB hingga 15.00

WIB berupa mengambil foto produk UMKM yang kemudian akan dipasarkan lewat media online serta mengambil video desa yang ditujukan untuk branding desa.

Kegiatan pengambilan foto produk yang dihasilkan oleh para pelaku usaha mikro dilakukan sebagai bentuk upaya untuk mengoptimalkan sektor UMKM melalui digitalisasi. Terdapat empat pelaku usaha mikro di Desa Gajah yang telah terdaftar dalam kegiatan ini. Empat pelaku usaha mikro tersebut

diantaranya, yakni :

Tabel 1 : Daftar nama produk yang dipasarkan secara online

\begin{tabular}{ll}
\hline No. & Nama Produk \\
1 & Makaroni Pak Sudarsono \\
2 & Tempe Sukron \\
3 & Tempe Gembus Bu Sriwati \\
4 & Makaroni J \& N \\
\hline
\end{tabular}

Mekanisme pemasaran produk yang dilakukan melewati beberapa tahapan. Tahap pertama adalah melakukan pengambilan foto dan video pembuatan produk secara langsung di Desa Gajah. Kemudian, tahap kedua yaitu melakukan editing foto produk yang telah diambil menjadi bentuk poster dan banner. Tahap terakhir yaitu memasarkan produk yang telah difoto dalam media online atau instagram kelompok 
KKN 58. Berikut adalah beberapa contoh poster dan banner dari produk UMKM yang telah dibuat:

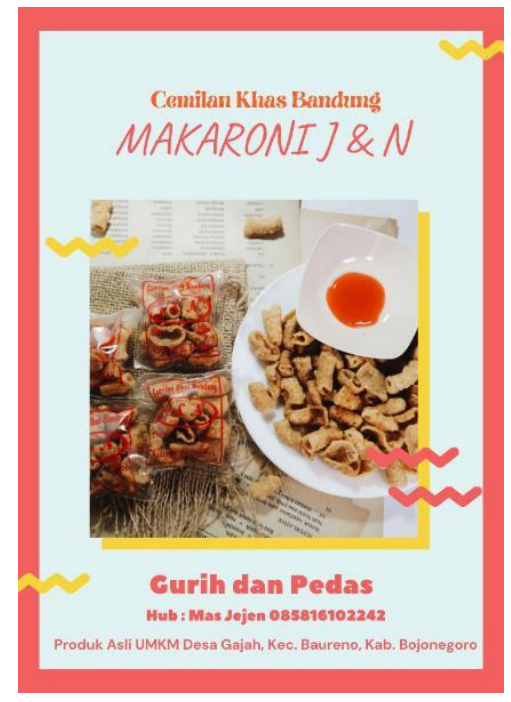

Gambar 1 : Salah satu contoh poster produk UMK

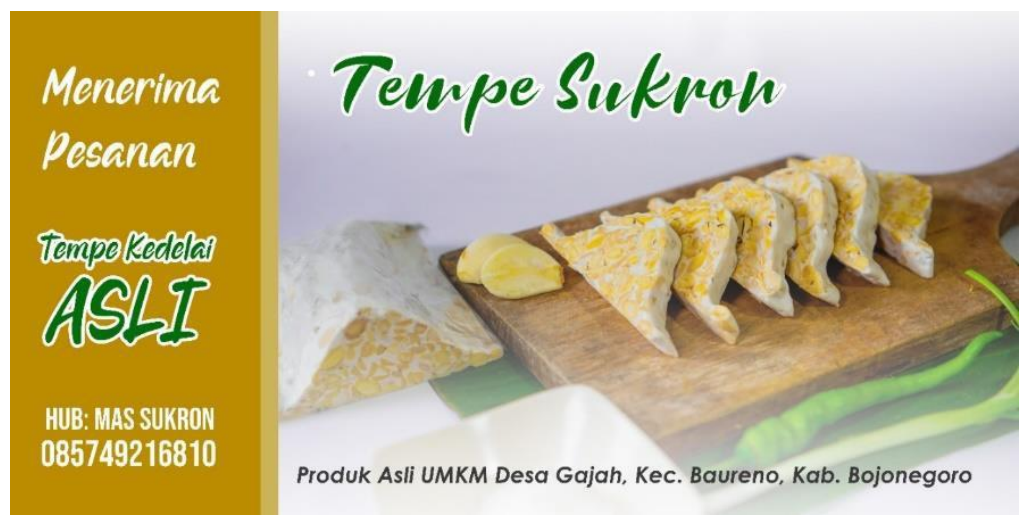

Gambar 2 : Salah satu contoh banner produk UMKM

Adanya program pemasaran atau branding UMKM di Desa Gajah ini diharapkan akan membantu memulihkan pelaku sektor UMKM di masa pandemi seperti ini. Adanya program ini juga memberikan pemahaman pada masyarakat Desa Gajah mengenai penggunaan digitalisasi dalam melakukan pemasaran produk. Branding UMKM berguna dalam pengenalan dan penanaman merek dalam benak konsumen. Melalui branding, produk dapat dikenali oleh konsumen secara menyeluruh dan utuh, Strategi yang dijalankan oleh KKN KELOMPOK 58 ini sebagaimana di dalamnya terdapat teori konstruksi sosial, UMKM dapat memenuhinya sebagai berikut menggunakan instrumen pada teori konstruksi sosial hal yang sama pula dijalankan melalui tiga bentuk brand association dari strategi dan bentuk brand association inilah yang nanti untuk mewujudkan berjalannya bisnis tersebut.

Selain program tersebut, terdapat program unggulan lain yang dilakukan oleh kelompok kami. Program tersebut adalah pengenalan desa melalui video pesona Desa Gajah. Dalam video tersebut memuat beberapa hal yang menunjukkan ciri khas atau 
karakteristik dari Desa Gajah yang berbeda dari desa lainnya. Video branding desa tersebut mencakup tiga unsur utama yakni potensi wisata, aktivitas penduduk serta harmonitas desa. Tujuan dari pembuatan video pesona Desa Gajah adalah untuk meningkatkan potensi desa dengan mengenalkan ke masyarakat serta bertujuan untuk menginspirasi atau memelopori desa lainnya agar membuat video profil desa seperti yang telah diterapkan di Desa Gajah.

Namun terdapat beberapa hal yang perlu diperhatikan. Program pemasaran produk secara online yang dipelopori oleh kelompok $58 \mathrm{KKN}$ harus memperhatikan beberapa hal. Salah satu hal utama yang harus diperhatikan adalah kemampuan dan pengetahuan warga desa terutama pelaku sektor UMKM mengenai pemasaran produk secara online. Karena realitas membuktikan bahwa para pelaku usaha di Desa Gajah mayoritas tidak memahami sistem pemasaran dengan media online sehingga memerlukan sosialisasi dan bimbingan berkelanjutan agar masyarakat bisa menerapkan hal tersebut. Selain itu faktor lain yang menyebabkan kurangnya pemahaman di kalangan warga Desa Gajah mengenai digitalisasi adalah ketidakmerataan kepemilikan gadget. Faktor lainnya adalah keterbatasan akses sosial media di kalangan masyarakat Desa Gajah. Fakta lapangan menunjukkan bahwa mayoritas masyarakat Desa Gajah tidak memilik akun sosial media, sehingga hal ini juga menjadi salah satu penghambat dalam melakukan pemasaran produk dengan media online.

\section{PENUTUP}

\section{A. Simpulan}

Program Unggulan KKN Kelompok 58 adalah untuk mengoptimalkan potensi wisata Bukit Cinta dan UMKM (Usaha Mikro Kecil Menengah) di Desa Gajah Kecamatan Baureno Kabupaten Bojonegoro akibat keterpurukan yang disebabkan oleh pandemi COVID-19. Kegiatan ini ditujukan untuk para pelaku usaha mikro di Desa Gajah yang dilakukan pada tanggal 2 Februari 2021 pada pukul 09.00 - 15.00 WIB berupa mengambil foto produk UMKM yang kemudian akan dipasarkan lewat media online serta mengambil video desa yang ditujukan untuk branding desa.

Kedua kegiatan tersebut diharapkan dapat membantu memulihkan perekonomian sektor UMKM dan meningkatkan potensi Desa Gajah selama masa pandemi. Adanya program ini juga memberikan pemahaman pada masyarakat Desa Gajah mengenai pentingnya penggunaan digitalisasi dalam melakukan pemasaran produk yang mana dapat mem-branding UMKM miliknya dalam pengenalan dan penanaman merek kepada konsumen serta dapat mem-branding pesona yang dimiliki Desa Gajah yaitu potensi wisata Bukit Cinta. Program tersebut dilakukan untuk pengenalan desa melalui video pesona Desa Gajah. Dalam video tersebut memuat beberapa hal yang menunjukkan ciri khas atau karakteristik dari Desa Gajah yang berbeda dari desa lainnya. Video branding desa tersebut mencakup tiga unsur utama yakni potensi wisata, aktivitas penduduk, dan harmonitas desa.

\section{B. Saran}

Untuk mengeksekusi kedua program unggulan tersebut, masyarakat Desa Gajah dianjurkan untuk mengetahui adanya pemahaman tentang konsep digitalisasi dalam 
bentuk pemasaran produk UMKM secara online dan mem-branding potensi wisata Bukit Cinta di Desa Gajah. Namun, kenyataan nya mayoritas para pelaku usaha UMKM dan masyarakat di Desa Gajah tidak memahami sistem pemasaran dengan media online, adanya ketidakmerataan dalam kepemilikan gadget, dan keterbatasan akses sosial media sehingga dapat menghambat perekonomian masyarakat Desa Gajah. Untuk mengatasi permasalahan tersebut, KKN Kelompok 58 Universitas Airlangga telah melakukan berbagai kegiatan yang dapat memecahkan permasalahan hambatanhambatan tersebut dengan cara membantu:

1. Pengambilan foto dan video pembuatan produk secara langsung,

2. Melakukan editing foto produk yang telah diambil menjadi bentuk poster dan banner, 3. Memasarkan produk yang telah difoto dalam media online atau instagram kelompok KKN 58,

4. Mem-branding pengenalan desa tepatnya wisata Bukit Cinta melalui video pesona Desa Gajah.

\section{DAFTAR PUSTAKA}

https://www.dw.com/id/bagaimana-pariwisata-indonesia-bertahan-di-tengahpandemi/a-54818132. (2020, September 6). Retrieved from www.dw.com.

Kriyantono, R. 2006. Teknik Praktis Riset Komunikasi. Jakarta: Kencana. 